\title{
A DIMENSÃO DO DIREITO AO ACESSO À JUSTIÇA E OS PRINCÍPIOS DA EFETIVIDADE DA JURISDIÇÃo E DA DURAÇÃo RAZOÁVEL DO PROCESSO
}

\author{
THE DIMENSION OF THE LAW TO ACCESS TO JUSTICE AND THE \\ PRINCIPLES OF EFFECTIVENESS OF JURISDICTION AND OF REASONABLE \\ DURATION OF THE PROCESS
}

\author{
${ }^{1}$ Taisa Cintra Dosso
}

\begin{abstract}
Resumo
O anseio do jurisdicionado quando busca a tutela estatal é a obtenção de um processo justo e célere. A garantia constitucional prevista no artigo $5^{\circ}$, inciso XXXV não é apenas a possibilidade de que o jurisdicionado possa exigir do Poder Judiciário uma decisão sobre seus conflitos, mas a garantia de que, sofrendo lesão ou ameaça em seus direitos, poderá exigir uma decisão que lhe dê o que tem direito, em tempo de aproveitá-la. O direito ao acesso à justiça prevê o acesso a uma ordem jurídica justa, atendendo ao princípio da efetividade da jurisdição e da duração razoável do processo.
\end{abstract}

Palavras-chave: justiça; garantia; efetividade; processo; celeridade.

\begin{abstract}
The desire of the court when seeking state tutelage is to obtain a fair and expeditious process. The constitutional guarantee provided for in article 5, paragraph $\mathrm{XXXV}$, is not only the possibility that the court may require the Judiciary to decide on its conflicts, but also the guarantee that, suffering injury or threat of its rights, it may require a decision that give what you have right, in time to take advantage of it. The right to access to justice provides access to a fair legal order, taking into account the principle of the effectiveness of the jurisdiction and the reasonable duration of the proceedings.
\end{abstract}

Keywords: justice; warranty; effectiveness; process; celerity.

\footnotetext{
${ }^{1}$ Graduada e Mestre em Direito pela Universidade Estadual Paulista Júlio de Mesquita Filho, UNESP - SP, (Brasil). Procuradora do Município de Ribeirão Preto - SP. E-mail: tatacin@yahoo.com
} 


\section{A DIMENSÃO DO DIREITO AO ACESSO À JUSTIÇA E OS PRINCÍPIOS DA EFETIVIDADE DA JURISDIÇÃO E DA DURAÇÃO RAZOÁVEL DO PROCESSO}

No direito processual civil moderno, o direito ao acesso à justiça está intimamente relacionado com os princípios da efetividade da jurisdição e da duração razoável do processo, sendo as novas ferramentas legalislativas como o novo Código de Processo Civil, bem como o processo digital, instrumentos que fortelecem essa relação, representando um avanço neste ramo da ciência do direito.

\section{A dimensão do direito ao acesso à justiça: direitos humanos, constitucionalização e instrumentalidade do processo}

$\mathrm{O}$ acesso à justiça, ou direito à tutela jurisdicional, é um direito humano fundamental, ligado à dignidade da pessoa humana, com previsão na Constituição Federal, artigo $5^{\circ}, \mathrm{XXXV}$, que determina que "a lei não excluirá da apreciação do Poder Judiciário lesão ou ameaça a direito."

Importante frisar que o artigo acima citado também é o fundamento para o direito constitucional do direito de ação, ou princípio da inafastabilidade da jurisdição, que não se confunde com o direito ao acesso à tutela jurisdicional, conforme precisa lição de Ricardo de Barros Leonel.

Segundo o autor, pode-se fazer as seguintes ponderações: a) o artigo $5^{\circ}, \mathrm{XXXV}$, da CF de 1.988 é o fundamento tanto do direito constitucional de ação ${ }^{2}$, como do direito à tutela jurisdicional; b) a tutela jurisdicional decorre do exercício do direito de ação, mas não se confunde com ele; c) o conceito de tutela jurisdicional identifica-se com a proteção, resultante do processo outorgada pelo Estado-juiz ao litigante vencedor; proteção essa que se projeta tanto no plano jurídico (proteção do patrimônio jurídico) como no plano prático (entrega do bem da vida, resultado concreto do processo para o vencedor) (LEONEL, 2010, p. 17).

Assim, em última análise, o direito de acesso à justiça ou à tutela jurisdicional busca

\footnotetext{
2 O direito de ação ou princípio da inafastabilidade da jurisdição, refere-se à possibilidade de deduzir pretensões em juízo, variando a concepção, em certa medida, de acordo com a teoria adotada a respeito do próprio conceito de direito de ação, considerado de forma abstrata (direito ao provimento jurisdicional), concreta (direito à sentença favorável) e mista ou eclética (direito à sentença de mérito tout court, favorável ou não). A respeito, ver: Buzaid (1986) e Lopes (2002). p.19).
} 
não apenas ingressar com uma ação judicial, nem buscar a sentença favorável, mas muito mais, busca o resultado concreto do processo, no plano prático, conforme se passa analisar.

Diante da dificuldade de definir o direito de acesso à justiça, Mauro Cappelletti e Bryant Garth (1988, p. 8) preferiram tomar o direito de acesso à justiça como aquele apto a dar ensejo às duas finalidades básicas do sistema jurídico: a) permitir-lhe funcionar como o mecanismo por meio do qual todas as pessoas, sem distinção, possam pleitear os seus direitos perante o Estado e, na mesma medida, ter resolvidos os litígios que as afligem; b) o sistema deve ser capaz de produzir resultados que se apresentem como justos, seja do ponto de vista do indivíduo, seja do social.

Na luta pelos direitos humanos, ganha realce a questão do acesso à justiça.

Está prevista na Declaração Universal dos Direitos do Homem, aprovada pela Assembleia Geral das Nações Unidas (ONU), em 10 de dezembro de 1.948, que em seu artigo VIII assim dispõe: "VIII. Todo homem tem direito a receber, dos tribunais nacionais competentes, remédio efetivo para os atos que violem os direitos fundamentais que lhe sejam reconhecidos pela constituição ou pela lei.” (ROBERT; SÉGUIN, 2000, p. 51-52).

Considerando a classificação tradicional dos direitos humanos em gerações ${ }^{3}$, bem como as finalidades básicas do sistema jurídico que Mauro Cappelletti e Bryant Garth entendem que devem ser alcançadas pelo direito de acesso à justiça, é possível afirmar que tal direito tem um aspecto individual, mas também social, sendo, portanto, pertencente aos direitos de primeira e segunda geração.

A garantia constitucional do acesso à justiça é consagrada na maior parte das Constituições dos Estados Democráticos de Direito, e nesse contexto está o Brasil, que já em sua Constituição de 1.934, bem como na de 1.946, já a previam, culminando com sua previsão no vigente Texto Político, como acima transcrito.

O conceito de acesso à justiça apresentou considerável evolução, significando, não apenas o acesso aos tribunais, mediante isenção de custas, taxas e emolumentos, mas também,

3 Segundo Carlos Weis, a classificação mais usualmente encontrada é a que identifica três categorias distintas de direito humanos, com características específicas decorrentes do valores que inspiraram sua criação, encontrados em momentos sucessivos da História. Os direitos de primeira geração, de inspiração liberal, referem-se aos direitos de autonomia e de defesa, que delimitam a atuação do Estado diante das liberdades individuais (direitos individuais). Já os de segunda geração, de cunho social, pressupõe o alargamento da competência estatal, requerendo a intervenção do Poder Público para reparar as condições materiais de existência de contingentes populacionais. Por fim, a terceira geração dos direitos humanos correspondem ao direito concernente a toda humanidade, como o direito ao meio ambiente, direito à paz, enfim (WEIS, 2006. p. 37-40). 
e principalmente, ao acesso ao direito, como bem observam Cinthia Robert e Elida Séguin (2000, p. 181).

Ao tratar da amplitude do conceito de acesso à justiça, Antônio Carlos de Araújo Cintra, Ada Pellegrini Grinover e Cândido R. Dinamarco (1999, p. 33-34), ensinam que acesso à justiça não se identifica com a mera admissão ao processo, mas, para sua integralidade, é preciso isso e muito mais:

\begin{abstract}
A ordem jurídico-positiva (Constituição e leis ordinárias) e o lavor dos processualistas modernos têm posto em destaque uma série de princípios e garantias que, somados e interpretados harmoniosamente, constituem o traçado do caminho que conduz as partes à ordem jurídica justa. $\mathrm{O}$ acesso à justiça é, pois, a ideia central a que converge toda a oferta constitucional e legal desses princípios e garantias. Assim, (a) oferecese a mais ampla admissão de pessoas e causas ao processo (universalidade da jurisdição), depois (b) garante-se a todas elas (no cível e no criminal) a observância das regras consubstanciam o devido processo legal, para que (c) possam participar intensamente da formação do convencimento do juiz que irá julgar a causa (princípio do contraditório), podendo exigir dele a (d) efetividade de uma participação em diálogo, tudo isso com vistas a preparar uma solução que seja justa, seja capaz de eliminar todo resíduo de insatisfação. Eis a dinâmica dos princípios e garantias do processo, na sua interação teleológica apontada para a pacificação com justiça.
\end{abstract}

Para assegurar a amplitude desta acessibilidade é que surge o poder e o dever do juiz de valorar os interesses humanos deflagrados na relação posta a exame, sob a ótica de preservação dos direitos fundamentais e tendo em vista a continuidade da vida em sociedade. Fala-se em observância à dupla dimensão dos direitos fundamentais (CRUZ, 2012, p. 152).

Assim, infere-se da evolução do conceito do direito de acesso à justiça previsto no artigo $5^{\circ}$, inciso XXXV, da Carta da República vigente que, não é garantido apenas o acesso a uma prestação jurisdicional, mas também, e principalmente, o acesso a uma tutela jurisdicional.

A primeira representa o acesso ao serviço judiciário que se instrumentaliza por meio do processo para a solução da lide, enquanto a segunda, representa a efetiva proteção e satisfação do direito, conforme leciona Humberto Theodoro Júnior (2001, p. 2) que:

[...] urge não confundir tutela com prestação jurisdicional (...). Assim, quando o provimento judicial reconhece e resguarda in concreto o Direito Subjetivo da parte, vai além da simples prestação jurisdicional e, pois, realiza a tutela jurisdicional. Todo litigante que ingressa em juízo, observados os pressupostos processuais e as condições da ação, tem direito à prestação jurisdicional (sentença de mérito ou prática de certo ato executivo); mas nem todo litigante faz jus à tutela jurisdicional.

Questão ainda pouco discutida, mas de grande relevância para a compreensão da 
dimensão do conceito aqui debatido é a respeito da natureza do direito ao acesso à justiça.

À primeira vista, o direito ao acesso à justiça parecer ter índole processual, posto que se dá mediante o exercício do direito de ação (CPC, art. 262 e art. 263), ensejando o nascimento do processo. Mas a questão não é tão singela.

$\mathrm{O}$ direito ao acesso à justiça retrata um direito de natureza eminentemente material, direito humano fundamental ligado à dignidade da pessoa humana. Trata-se de direito material ou substancial, como são os casos de direito à tutela cautelar, que nada mais é do que o direito material à segurança, assim como o direito à rescisão de sentença, que parecem ser direitos apenas processuais, mas que na verdade são materiais. Assim, a violação do direito ao acesso à justiça não se limita à norma processual, mas a violação ou supressão de direito fundamental da pessoa humana (SOUZA, 2012, p. 234-236).

A natureza material de acesso à justiça encontra respaldo em sua gravação como cláusula pétrea $\left(\mathrm{CF}\right.$, art. $60, \S 4^{\circ}, \mathrm{IV}$, da $\left.\mathrm{CF}\right)$, insuscetível de abolição, nem mesmo mediante emenda constitucional.

O direito em voga não se confunde com o direito de petição, previsto no artigo $5^{\circ}$, $\mathrm{XXXIV}, a, \mathrm{CF}$, de natureza política, conferido para que se possa reclamar, junto aos poderes públicos em defesa de direitos contra ilegalidade ou abuso de poder (NERY JÚNIOR, 1999, p. 94-95).

Tendo em vista o tema proposto, importante fazer algumas considerações de cunho processual referente ao direito de ação.

Da leitura do dispositivo constitucional (artigo $5^{\circ}, \mathrm{XXXV}$ ) infere-se que o Poder Judiciário, desde que haja plausibilidade da ameaça ao direito, é obrigado a efetivar o pedido de prestação jurisdicional aduzido pela parte regularmente.

E a necessidade de serem preenchidos as condições da ação e os pressupostos processuais, bem como a observância dos prazos prescricionais e decadenciais para o exercício do direito de ação, são previsões que, embora limitadoras, caracterizam-se pela plausibilidade e constitucionalidade ${ }^{4}$.

A esse respeito, vale transcrever as lições de Nelson Nery Jr. Segundo o autor,

[...] o direito de ação é um direito cívico e abstrato, vale dizer é um direito subjetivo à sentença tout court, seja essa de acolhimento ou de rejeição da pretensão, desde que

\footnotetext{
4 São as lições de Alexandre de Moraes, conforme se verifica na obra de Paulo e Alexandrino (2009, p. 145 146).
} 
preenchidas as condições da ação. [...] A necessidade de serem preenchidas as condições da ação (CPC art. 267, VI) e os pressupostos processuais (CPC, art. 267, IV), serem observados os prazos para o exercício do direito de ação, bem como de serem obedecidas as formas dos atos processuais significam limitações naturais e legítimas ao exercício do direito de ação (NERY JÚNIOR, 1999, p. 96-97).

Vencida a etapa de análise das condições da ação e dos pressupostos processuais, o desenvolvimento do processo, instaurado mediante ajuizamento da ação, deve se dar visando a efetivação do direito material supostamente violado. Nesse aspecto, remete-se ao estudo acima quanto às dimensões do conceito do direito ao acesso à justiça, oportunidade em que se traz estudo de Júlio Guilherme Müller (2013, p. 209), acerca das posições jurídicas para a concretização do acesso à justiça.

Segundo o autor, garantir, entretanto, o acesso ao Poder Judiciário ou ao mero direito de pleitear a intervenção do Estado em situações de crise, não basta. A prestação de uma tutela jurisdicional justa, efetiva, tempestiva, adequada e com a participação efetiva das partes, é a pedra angular de um Estado Democrático e de Direito que tem por fundamentos a cidadania e a dignidade da pessoa humana, e que se preocupa em assegurar o exercício dos direitos, da liberdade, da segurança, do bem-estar, do desenvolvimento, da igualdade e da justiça.

A concretização do direito ao acesso à justiça, em sua dimensão mais ampla, depende da prestação de uma tutela jurisdicional justa, efetiva, tempestiva, adequada e com a participação efetiva das partes.

A visão do acesso à justiça de forma tão louvável, tão eficaz, remete ao reconhecimento de um fenômeno ocorrente no direito processual civil conhecido como constitucionalização do processo civil. Trata-se da elevação do processo civil à ordem constitucional, na busca real de seu fim, atuando o processo não apenas como um procedimento que observe o devido processo legal, mas o caminho à ordem jurídica justa, em plena sintonia com os valores contidos na Constituição Federal de 1988.

Sobre a relação entre processo e Constituição, leciona Willis Santiago Guerra Filho (2000, p. 24-25), que no final dos anos sessenta e princípio dos anos setenta demarcou-se o advento de uma virtual renovação dos estudos do direito processual, quando se passou a realçar a importância da origem constitucional dos institutos processuais básicos. Cresceram, então, as análises da vinculação do processo com a constituição, ao ponto de se poder encarar o direito processual como uma espécie de direito constitucional aplicado, como o fez a Corte Constitucional alemã. 
O direito processual civil moderno reconhece o caráter constitucional de seu escopo maior, que é a pacificação social, estreitando sua relação com o direito material. Deixa de se arraigar ao formalismo exacerbado, tornando o processo mais dinâmico e autêntico, visando, sobretudo, compatibilizar-se com as normas constitucionais. Percebe-se, nesse enfoque da disciplina, o fortalecimento da ideia da instrumentalidade do processo, termo bastante utilizado pelos processualistas modernos.

A propósito, vale colacionar pensamento do Desembargador do Tribunal de Justiça de Santa Catarina, Pedro Manoel Abreu (2013, p. 158), que relaciona a constitucionalização do processo com sua instrumentalidade:

\footnotetext{
O direito processual civil mantém, embora ciência autônoma, afinidade intensa e indissociável com o direito constitucional. Este é fonte do direito processual civil, pois é justamente nele que se localizam os princípios fundamentais do processo. Tem o direito processual sua base no direito constitucional, que lhe fixa os fundamentos, notadamente quanto ao direito de ação e de defesa e ao exercício da jurisdição. Por detrás dos princípios que informam as normas processuais, sempre está um comando constitucional. Interligam-se, dessa forma, os preceitos constitucionais e os princípios que informam o processo.

O direito processual é inerente à Constituição, porque muito mais do que mero instrumento técnico, é instrumento ético de efetivação de garantias constitucionais. Nessa vereda o direito processual pode ser vislumbrado como uma espécie de direito constitucional aplicado. Apesar dos esforços no sentido de adaptar a dogmática aos ditames de nível constitucional, pautados diretamente com o processo, permanece inexplorada ainda a via que pode levar a uma completa reformulação do modo de concebê-lo, estruturado de conformidade com os imperativos de um Estado de direito social e democrático.
}

O estudo do acesso à justiça, em sua dimensão mais ampla, denota a visão moderna do direito processual civil, intimamente ligado aos princípios e garantias constitucionais e, por conseguinte, ao direito material, evidenciando o caráter instrumental do processo, tão bem analisado por Antônio Carlos de Araújo Cintra, Ada Pellegrini Grinover e Cândido R. Dinamarco (1999, p. 41-42).

Segundo os renomados processualistas, o processo é um instrumento a serviço da paz social, havendo um conceito de instrumentalidade sob o aspecto positivo e outro sob o aspecto negativo. Este último refere-se à tradicional postura, legítima também, consistente em alertar para o fato de que ele não é um fim em si mesmo, não devendo, na prática cotidiana, ser guinado à condição de fonte geradora de direitos. Um reflexo desse aspecto negativo da instrumentalidade do processo é o princípio da instrumentalidade das formas, segundo o qual as exigências formais do processo só merecem ser cumpridas à risca, sob pena de invalidade dos atos, na medida em que isso seja indispensável para a consecução dos objetivos desejados, 
citando os autores como exemplo, nesse caso, a hipótese em que não se anula o processo por vício de citação, se o réu compareceu e se defendeu (CINTRA; GRINOVER; DINAMARCO, 1999, p. 41-42).

Já a instrumentalidade sob a ótica positiva diz respeito à relação que une o sistema processual à ordem jurídico-material e ao mundo das pessoas e do Estado, com destaque à necessidade de predispô-lo ao integral cumprimento de todos os seus escopos sociais, políticos e jurídico. A instrumentalidade sob o aspecto positivo revela a necessidade do processo ser efetivo, adotando-se um sistema processual capaz de servir de eficiente caminho à ordem jurídica justa. E, com a lógica ímpar de sua obra, Antônio Carlos de Araújo Cintra, Ada Pellegrini Grinover e Cândido R. Dinamarco (1999, p. 41), finalizam ensinando que não só é preciso ter a consciência dos objetivos a atingir (escopos sociais, políticos e jurídico), como também conhecer e saber superar os óbices econômicos e jurídicos que se antepõe ao livre acesso à justiça.

E nesse contexto, são óbices à efetividade do processo e, por conseguinte, ao seu caráter positivamente instrumental: a) a admissão ao processo ou ingresso em juízo, devendo ser eliminadas as dificuldades que impeçam ou desanimem as pessoas de litigar ou dificultem o oferecimento de defesa adequada, dando-se integral cumprimento à garantia constitucional de assistência jurídica integral e gratuita (art. $5^{\circ}$, LXXIV, CF), bem como viabilizar cada vez mais não apenas a defesa dos direitos e interesses individuais, mas também dos direitos e interesses transindividuais; b) o "modo-de-ser do processo", devendo ser respeitadas todas as garantias processuais, como o devido processo legal, contraditório, bem como assegurada a participação adequada do magistrado na busca por elementos para a instrução da ação; c) a justiça das decisões, em que o juiz deve pautar-se pelo critério de justiça, ao interpretar e enquadrar os fatos às normas jurídicas, bem como ao valorar as provas, não exigindo prova tão precisa e exaustiva dos fatos, que torne impossível a demonstração destes e impeça o exercício do direito material pela parte e; por fim, d) a utilidade das decisões, devendo o processo dar a quem tem um direito tudo aquilo e precisamente tudo aquilo que ele tem o direito de obter, evitando-se, ao máximo, tomadas de posição que tornem acanhadas ou mesmo inúteis as medidas judiciais, deixando resíduos de injustiça (CINTRA; GRINOVER; DINAMARCO, 1999, p. 34-35).

Assim, deve-se prestigiar os instrumentos processuais novos que visam dar efetividade e celeridade ao processo, e que garantam a utilidade da decisão. 


\section{O acesso à justiça e os princípios da efetividade da jurisdição e da duração razoável do processo}

E neste ponto do estudo sobre o princípio constitucional do acesso à justiça, importante se aprofundar a relação deste com os princípios da efetividade da jurisdição, que assegura a necessidade de uma tutela jurisdicional adequada e efetiva, que satisfaça a pretensão material trazida a juízo, e com o princípio da duração razoável do processo, garantidor de uma prestação jurisdicional célere.

E assim, passa-se ao estudo do princípio da efetividade da jurisdição.

$\mathrm{O}$ princípio de efetividade da jurisdição, decorrente do artigo $5^{\circ}$, inciso $\mathrm{XXXV}, \mathrm{CF}$, representa um dos maiores desafios aos operadores do direito modernamente. Segundo a máxima Chiovendiana ${ }^{5}$, cuida-se da preocupação em assegurar ao titular do direito tudo aquilo e exatamente aquilo que obteria caso seu direito fosse observado e cumprido voluntariamente, valendo-se do processo como instrumento a atingir essa finalidade. Implica no reconhecimento da existência de um direito à proteção jurisdicional adequada e efetiva.

Mecanismos processuais adequados para tutelar o direito material representam meio caminho andado para a efetividade. Uma tutela processual adequada serve de instrumento para a imprescindível e almejada satisfação do direito. A efetividade, no entanto, nem sempre se confunde com a adequação, apesar de estarem imbricadas de tal forma que, às vezes, uma acaba levando à outra. Em alguns momentos, o operador do direito e o magistrado se valem das ferramentas mais aptas para tutelar o direito sem conseguir, ao final, apresentar um resultado eficaz e que proporcione à parte tudo aquilo e exatamente aquilo a que ela teria direito. Em outros casos, a subutilização do instrumental fornecido pelo ordenamento jurídico acaba impedindo que o resultado almejado se produza. Há, assim, uma eficácia concreta que também deve ser perseguida. A adequação instiga o operador a buscar o instrumental mais apto às exigências do direito. Já a efetividade se preocupa com o plano da eficácia, com a satisfação dos interesses tutelados. Enquanto na primeira prepondera uma mediação entre objetivos perseguidos e meio utilizados, na segunda se comparam os objetivos perseguidos com os

\footnotetext{
5 Giuseppe Chiovenda foi o primeiro a idealizar a efetividade como escopo maior do processo (CHIOVENDA, 2003).
} 
resultados apresentados (MÜLLER, 2013, p. 213).

Segundo Kazuo Watanabe (2012, p. 20-24), são desenvolvidos basicamente dois métodos de pensamentos em busca da efetividade: um pela perspectiva de direito material e o outro pela perspectiva do direito processual. Para aqueles, cada ação de direito material corresponde necessariamente uma ação de direito processual, enquanto para os últimos, o processo deve dar o que ele tenha direito de conseguir.

Assim, por essas duas perspectivas, ou por esses dois métodos de pensamento, são desenvolvidos os estudos em busca dessa efetividade, ou seja, da maior aproximação, ou mesmo de um acoplamento mais perfeito, entre direito material e o direito processual. Desembocam os resultados desses estudos num mesmo estuário, mas ainda não se harmonizam de todo - à semelhança do que ocorre na natureza, que mostra exemplos de águas de cores diferentes de dois rios que, após o encontro, correm paralelamente por longa distância até que se misturem por completo. No entanto, independente da perspectiva adotada, o que importa é a tutela efetiva de todos os direitos da parte, pois se de um lado existe o direito material, de outro, há técnicas de direito processual que propiciam a tutela do direito.

Mas conclui Watanabe (2012, p. 25) que ambas as perspectivas são igualmente relevantes. Se de um lado há exigências próprias do direito material por uma adequada tutela, há de outro as técnicas específicas do direito processual, não somente quanto à natureza do provimento, como também no tocante à duração do processo, à eventual antecipação da tutela, à intensidade e amplitude da cognição, e a muitos outros aspectos.

Frisa-se que não se trata de privilegiar um direito (no caso, o direito material) a outro (no caso, o direito processual). Mas sim de buscar uma correlação, porque não harmoniosa e coerente, entre os dois direitos, considerando a razão de ser de cada qual, na busca de um objetivo maior, que é a satisfação da pretensão deduzida em juízo, com vistas à pacificação social.

José Roberto dos Santos Bedaque (2011a, p. 59-65) faz importante relação entre os escopos do processo e a técnica processual. Segundo o autor, para se ter acesso à ordem jurídica justa é necessário haver uma flexibilização do sistema processual, consistente em conciliar a técnica processual com seu escopo, com vistas à efetivação do processo (BEDAQUE, 2011b).

Leciona o autor que a principal missão do processualista é buscar alternativas que favoreçam a resolução dos conflitos de modo seguro e tempestivo, mediante tutelas aptas a afastar a crise de direito material, realizando concretamente a vontade do legislador. Para tanto, 
por evidente, não se pode prescindir da técnica. Embora necessárias à eficiência do método e efetividade do resultado, as alternativas adotadas no sistema processual são meios destinados a alcançar escopos. Por isso, como bem adverte, devem ocupar seu devido lugar, como instrumento de trabalho e não como fim em si mesmo. Não se trata de desprezar os aspectos técnicos do processo, mas apenas de não se apegar ao tecnicismo exacerbado, que acaba sempre em “obsessão em detrimento do fim”. A técnica deve servir de meio para que o processo atinja seu resultado. Segundo o autor, critica-se não o dogmatismo, mas o dogmatismo puro e exagerado, o "formalismo indiferente aos reais problemas a serem solucionados no processo" (BEDAQUE, 2011a, p. 62), considerando virtuoso o processualista que consegue harmonizar esses dois aspectos, o que implica a capacidade para construir um sistema processual tecnicamente eficaz, ou seja, apto a alcançar seus escopos de maneira adequada.

Abordando também a relação entre os escopos do processo e técnica processual, Cândido Rangel Dinamarco (2009, p. 266-267), alerta que é preciso:

[...] conciliar o aspecto instrumental do processo, que é realidade ética porque permeado dos influxos dos valores substanciais eleitos pela nação, com a necessidade de operacionalizar meios para a consecução do que se deseja. Toda técnica jurídica justifica-se, afinal, pela sua indispensável convergência aos ditames éticos da sociedade, infiltrados na essência do direito.

Importante também ressaltar que a aplicação desse princípio gera algumas questões relacionadas à compatibilização com outros princípios constitucionais processuais, como o princípio do devido processo legal e do contraditório.

Mas a questão da efetividade não se limita apenas à relação entre o direito material e o direito processual como acima exposto, com vistas à tutela jurisdicional adequada e efetiva. Há quem analise esse princípio sob um enfoque mais amplo, menos técnico sim, mas não menos importante.

Ao tratar sobre a dinâmica da justiça, Cesar Luiz Pasold (2013, p. 185), diz que se faz necessário dois fatores estratégicos a saber, o acesso e a efetivação. $\mathrm{O}$ acesso é a garantia constitucional já aqui abordada, com previsão constitucional (art. $5^{\circ}, \mathrm{XXXV}, \mathrm{CF}$ ). Quanto à efetivação da justiça, o autor dá um enfoque mais amplo, no sentido de haver uma dependência de uma série de fatores, entre os quais se destaca as necessárias condições ao trabalho eficiente e eficaz do Poder Judiciário, em especial a quantidade e qualidade dos recursos humanos, recursos financeiros e materiais e a disponibilidade e funcionalidade tecnológica. Mas, 
sobretudo, finaliza, a efetivação da justiça supõe a disseminação social da consciência jurídica e o trabalho eficaz e eficiente dos atores judiciais.

E ao analisar as causas da disfuncionalidade da Justiça, o Desembargador do Tribunal de Justiça do Estado de São Paulo, José Renato Nalini (2013, p. 94), assim questiona e responde:

\begin{abstract}
Essa justiça com atribuição de dar a cada um o que é seu, sem outras veleidades, porque não funciona? Por uma série de causas. A primeira delas é a síntese de todas as demais: os responsáveis pela Justiça não se aperceberam - ao menos com a consciência capaz de suscitar imprescindível reação - de que o mundo é outro. $\mathrm{O}$ mundo mudou. O ritmo da sociedade se alterou. A noção de direito foi profundamente transformada. O funcionamento da máquina está longe de acompanhar tais mutações.
\end{abstract}

Desta feita, seja pela ótica técnica, seja pela ótica estrutural, é possível afirmar que os rumos do processo civil moderno exigem dos operadores do direito uma postura mais comprometida com a concretização do acesso à justiça em seu sentido mais amplo, com vistas à pacificação social, albergando-se as evoluções que o tempo impõe, como, por exemplo, com a aplicação eficaz dos novos instrumentos processuais.

Nesse particular, cabível a análise do princípio da duração razoável do processo, também previsto na Constituição Federal.

A demora do processo sempre foi um entrave para a efetividade do direito de acesso à justiça. Não tem sentido que o Estado pró́ba a justiça de mão própria e não confira ao cidadão um meio adequado e tempestivo para a solução dos conflitos. Se o tempo do processo prejudica a parte que tem razão, seria ingenuidade imaginar que a demora do processo não beneficia justamente àqueles que não têm interesse no cumprimento das normas (MARINONI, 2008a, p. 2).

O princípio da duração razoável do processo está previsto no art. $5^{\circ}$, inciso LXXVIII, da Constituição Federal, por força da Emenda Constitucional nº 45, de 08 de dezembro de 2004. Estabelece o mencionado dispositivo que "a todos, no âmbito judicial e administrativo, são assegurados a razoável duração do processo e os meios que garantam a celeridade de sua tramitação."

Antes mesmo da Emenda Constitucional n 45/2.004, o princípio da duração razoável do processo já estava presente em nosso ordenamento jurídico, em razão do disposto no art. $8^{\circ}$, I, do Pacto de São José da Costa Rica, que previa ser direito fundamental da pessoa humana um processo com duração razoável, conforme artigo abaixo transcrito: 
Toda pessoa terá o direito de ser ouvida, com as devidas garantias e dentro de um prazo razoável, por um Juiz ou Tribunal competente, independente e imparcial, estabelecido anteriormente por lei, na apuração de qualquer acusação penal formulada contra ela, ou na determinação de seus direitos e obrigações de caráter civil, trabalhista, fiscal ou de qualquer natureza.

Segundo a Convenção Europeia para a Proteção dos Direitos Humanos e Liberdades Fundamentais, o Poder Judiciário que não cumpre com suas funções dentro de um prazo razoável, é uma justiça inacessível (CAPELLETTI; GARTH, 1988, p. 20-21).

Importante frisar que o princípio em estudo encontra fundamento em outro princípio processual já vigente, o princípio da economia processual, segundo o qual a atividade jurisdicional deve propiciar o máximo de resultados com o mínimo de esforços.

Segundo o princípio da duração razoável do processo, no caso, considerando objeto deste estudo, do processo judicial, deve ser assegurado a todo jurisdicionado a tramitação de um processo por um tempo que não seja tão longo a ponto de gerar ineficácia do provimento final pretendido, pois justiça tardia nada mais é do que injustiça flagrante (CAMARGO; CARVALHO, 1988, p. 85-84).

Quando houve a inclusão do inciso LXXVIII no rol do artigo $5^{\circ}$ da Constituição Federal, houve discussão no sentido de sua desnecessidade, posto que óbvia, o que não se concorda haja vista a importância da elevação de qualquer direito ao patamar de direito fundamental.

A propósito, Nelson Nery Júnior (1999, p. 40) leciona que:

[...] bastaria a Constituição Federal de 1988 ter enunciado o princípio do devido processo legal, e o caput e a maioria dos incisos do art. $5^{\circ}$ seria absolutamente despicienda. De todo modo, a explicitação das garantias fundamentais derivadas do devido processo legal, como preceitos desdobrados nos incisos do art. $5^{\circ}, \mathrm{CF}$, é uma forma de enfatizar a importância dessas garantias, norteando a administração pública, o legislativo e o judiciário para que possam aplicar a cláusula sem maiores indagações.

Discorrendo sobre o princípio da duração razoável do processo, Paulo Hoffman (2008, p. 328-329) conclui que o mais eficiente critério para definição do que venha a ser a "razoável duração" seja realmente o adotado pela Corte Europeia dos Direitos do Homem, o critério da posta in gioco: a) complexidade do caso; b) comportamento das partes; c) atuação dos juízes, 
dos auxiliares e da jurisdição.

Assim, a avaliação do prazo razoável de um processo deve ser feita caso a caso, levando em conta os critérios acima apontados, sem prejuízo de outros critérios como o critério geográfico (local do processo) e estrutural (quantidade de juízes e auxiliares da jurisdição).

Falar em tempo processual remonta à discussão clássica sobre as duas exigências do processo, geralmente contrastantes da justiça, ou seja, a celeridade e a ponderação, analisadas já pelos clássicos processualistas como Calamandrei, Carnelutti e Barbi, citados por Cândido Rangel Dinamarco (2009a, p. 273-274), que a respeito leciona:

\begin{abstract}
Sabe-se que a busca da verdade, na instrução processual, toma tempo; e que o passar do tempo, além de sujeitar a riscos de deterioração o próprio resultado jurídico do processo, prolonga as angústias do conflito e o estado de insatisfação que o serviço jurisdicional visa a eliminar. Com essa razão, foi dito que o tempo é inimigo do processo e que contra ele, para evitar os males que pode causar, o juiz deve estar em estado permanente de guerra entrincheirada. Por isso é que em certas situações o angustiante desafio da tensão entre conhecimento e ignorância há de ser contornado e o sistema exige que o juiz se conforme e pacifique sem haver chegado ao ponto ideal de assimilação da verdade. A boa técnica processual incumbe o estabelecimento do desejado racional e justo equilíbrio entre as duas exigências opostas, para que não se comprometa a qualidade do resultado da jurisdição por falta de conhecimento suficiente, nem se neutralize a eficácia social dos resultados bem concebidos, por inoportunidade decorrente da demora.
\end{abstract}

E como exemplos de reflexos ${ }^{6}$ da aplicação da garantia de duração razoável do processo na legislação já em vigor, pode-se citar os prazos processuais e as preclusões, a extinção do processo por abandono de causa, as sanções processuais como a litigância de máfé e o ato atentatório à dignidade da justiça, a execução provisória e as tutelas de urgência e a tutela antecipada por "abuso de direito de defesa" ou "manifesto propósito protelatório do réu (art. 273, II, do CPC), a qual se trata da forma já positivada em nosso ordenamento jurídico, da tutela de evidência.

Não se deve, ainda, confundir o perigo da demora com o direito à decisão dentro de prazo razoável, ou seja, ainda que não venha a perecer o direito pela demora, deve o Judiciário estar atento em respeito ao direito à duração do processo, evitando o chamado dano marginal.

Conforme precisa definição de Italo Andolina (apud HOFFMANN, 2008, p. 332-333), o dano marginal é aquele que o processo e sua duração causam à parte, independentemente do prejuízo já sofrido pelo descumprimento da obrigação ou desrespeito a direito, o qual será de

6 Esses reflexos são citados por GASPARETTI, 2013, p. 232-236. 
algum modo reparado pelo processo. Até pode o dano marginal de alguma forma ser recomposto, seja pela aplicação de multa, correção monetária, porém deverá ser de todo modo evitado e minimizado.

O direito constitucional à razoável duração do processo impõe a observância pelos operadores do direito ${ }^{7}$ da necessidade de se evitar o chamado dano marginal do processo, o qual, por si só, já acarreta muitos prejuízos aos jurisdicionados.

Por evidente que a duração razoável do processo esbarra em uma série de problemas de difícil solução e que nem sempre se apresentam de modo uniforme. A constitucionalização deste direito denota sua importância e total sintonia com os rumos do direito processual civil moderno, na busca de um amplo acesso à justiça.

É preciso sim que todos os envolvidos no processo estejam engajados em assegurar sua duração razoável, sem prejuízo de outros princípios e garantias processuais igualmente relevantes. Além disso, os instrumentos jurídicos que surgem no sentido de atender esse princípio devem ser prestigiados e aplicados, como é o caso, por exemplo, da tutela da evidência, ou tutela de evidência, também prevista no novo Código de Processo Civil, que é uma espécie do gênero tutela diferenciada, baseada não na clássica urgência, mas na evidência do direito invocado.

E para finalizar esse tópico, passo a transcrever lúcido pensamento do Desembargador paulista José Renato Nalini (2013, p. 93-97), sobre como assegurar o legítimo acesso à justiça:

A comunidade jurídica não tem sido criativa - ao menos na medida desejável - para adotar alternativas processuais ajustadas às necessidades contemporâneas. $\mathrm{O}$ legislador até que fez sua parte. Aprovou as recentes leis processuais que eliminam alguns gargalos na duração infinita dos processos, propõe a justiça virtual com a gradual redução do uso do papel, amplia os poderes do juiz de primeiro grau para que adote providências garantidoras de presteza na prestação jurisdicional. Aqui se inserem a possibilidade de antecipação de tutela, o bom uso das medidas liminares, a eliminação do processo de execução após o percurso da via de conhecimento. A barreira continua a ser cultural. A mentalidade tradicional resiste à adoção de procedimentos mais singelos, converte o processo em finalidade em lugar de considerá-lo ferramenta de realização do justo. Sofistica a prestação jurisdicional e investe na valorização de óbices processuais impedientes da apreciação do mérito. Assim o apreço às fórmulas de acolhimento de preliminares, o cultivo das nulidades, as questões incidentais e prejudiciais, tudo o que na prática vai desaguar no julgamento meramente processual da lide. A formação forense ainda é essencialmente adversarial e educa o profissional do direito para a pugna civilizada do processo. Não se estima as técnicas de conciliação, de argumentação, de persuasão, que tornariam concreta a efetiva disseminação das práticas alternativas à justiça convencional.

7 Refere-se aos operadores do direito e não apenas aos órgãos julgadores, pois que muitas vezes o processo se prolonga também em razão de conduta das partes. 
Desse modo, a dimensão do conceito do direito de acesso à justiça e a concretização dos princípios da efetividade da jurisdição e da duração razoável do processo recebe com boas vindas a justiça virtual, já em funcionamento em todo o Estado de São Paulo, bem como a nova legislação processual civil, o novo Código de Processo Civil, mas depende, também, da transposição de uma barreira cultural da comunidade jurídica, como bem acentua o Desembargador José Renato Nalini.

É o moderno direito processual civil, que reconhece a importância do procedimento e do formalismo, não o exacerbado, mas que se relaciona com o direito material de tal forma que reconhece a natureza essencialmente humana da ciência do direito, como instrumento de pacificação social.

\section{Referências}

ABREU, P. M. O novo processo civil imantado pelo constitucionalismo contemporâneo e a desconstrução da tradição científico-racional do processo. In: LAMY, E. (Org.). Processo civil em movimento: diretrizes para o novo CPC. São Paulo: Conceito, 2013. p. 148-159.

BEDAQUE, J. R. S. Direito e processo. São Paulo: Malheiros, 2011a.

BEDAQUE. J. R. S. Efetividade do processo e técnica processual. São Paulo: Malheiros, $2011 b$.

BUZAID, A. Ação declaratória do direito brasileiro. 2. ed. São Paulo: Saraiva, 1986.

CAMARGO, D. M.; CARVALHO, F. B. F. L. O processo como instrumento concretizador (ou negação) de princípios fundamentais. In: CAPPELLETTI, M.; GARTH, B. (Orgs.). Acesso à justiça. Tradução Ellen Gracie Northfleet. Porto Alegre: Sergio Antonio Fabris, 1988, p. 6589.

CAPPELLETTI, M.; GARTH, B. (Orgs.). Acesso à justiça. Tradução Ellen Gracie Northfleet. Porto Alegre: Sergio Antonio Fabris, 1988.

CHIOVENDA, G. A ação no sistema dos direitos. São Paulo: Líder, 2003.

CINTRA, A. C. A.; GRINOVER, A. P.; DINAMARCO, C. R. Teoria geral do processo. 15. ed. São Paulo: Malheiros, 1999. 
CRUZ. E. M. O acesso à justiça e a liberdade provisória no direito processual penal brasileiro. In: SIQUEIRA, D. P.; OLIVEIRA, F. L. (Orgs.). Acesso à justiça: uma perspectiva da democratização da administração da justiça nas dimensões social, política e econômica. Birigui (SP): Boreal, 2012. p.148-163.

DINAMARCO. C. R. A instrumentalidade do processo. São Paulo: Malheiros, 2009.

GASPARETTI, M. V. A duração razoável do processo e as reformas da lei processual. In: LAMY, E. (Org.). Processo civil em movimento: diretrizes para o novo CPC. São Paulo: Conceito, 2013. p. 229-241.

GUERRA FILHO, W. S. Teoria processual da constituição. 2. ed. São Paulo: Celso Bastos Editor; Instituto Brasileiro de Direito Constitucional, 2000.

HOFFMANN, P. Princípio da duração razoável do processo. In: CASTRO LOPES, M. E.; OLIVEIRA NETO, O. (Coords.). Princípios processuais civis na constituição. Rio de Janeiro: Elsevier, 2008. p. 321-345.

LEONEL, R. B. Tutela jurisdicional diferenciada. São Paulo: Revista dos Tribunais, 2010.

LOPES, J. B. Ação declaratória. 5. ed. São Paulo: Revista dos Tribunais, 2002.

MARINONI, L. G. Técnica processual e tutela dos direitos. 2. ed. rev. e atual. São Paulo: Revista dos Tribunais, 2008.

MÜLLER, J. G. Tutela adequada, afetiva, tempestiva e justa (posições jurídicas para a concretização do acesso à justiça). In: LAMY, E. (Org.). Processo civil em movimento: diretrizes para o novo CPC. São Paulo: Conceito, 2013. p. 209-216.

NALINI, J. R. Desafios do processo contemporâneo. In: LAMY, E. (org.). Processo civil em movimento: diretrizes para o novo CPC. São Paulo: Conceito, 2013. p. 93-97.

NERY JUNIOR, N. Princípios do processo civil na constituição federal. 5. ed. rev. e ampl. São Paulo: Revista dos Tribunais, 1999.

PASOLD. C. L. Processo, acesso e efetivação da justiça. In: LAMY, E. (Org.). Processo civil em movimento: diretrizes para o novo CPC. São Paulo: Conceito, 2013. p. 183-192.

PASSOS, J. J. C. A função social do processo. In: WAMBIER, L. R. (Coord.). As novas fronteiras do direito processual. São Paulo: RCS, 2007.

PAULO, V.; ALEXANDRINO, M. Direito constitucional disciplinado. 4. ed. Rio de Janeiro: Forense; São Paulo: Método, 2009. 
ROBERT, C.; SÉGUIN, E. Direitos humanos, acesso à justiça: um olhar da defensoria pública. Rio de Janeiro: Forense, 2000.

SOUZA. G. A. Processo e acesso à justiça. In: SIQUEIRA, D. P.; OLIVEIRA, F. L. (Orgs.). Acesso à justiça: uma perspectiva da democratização da administração da justiça nas dimensões social, política e econômica. Birigui (SP): Boreal, 2012. p. 229-248.

THEODORO JUNIOR, H. Tutela jurisdicional de urgência: medidas cautelares e antecipatórias. 2. ed. Rio de Janeiro: América Jurídica, 2001.

WAMBIER, L. R. (Coord.). As novas fronteiras do direito processual. São Paulo: RCS, 2007.

WATANABE, K. Da cognição no processo civil. 4. ed. São Paulo: Saraiva, 2012.

WEIS, C. Direitos humanos contemporâneos. São Paulo: Malheiros, 2006. 